\title{
SOLE: Applying Semantics and Social Web to Support Technology Enhanced Learning in Software Engineering
}

\author{
Ricardo Colomo-Palacios ${ }^{1}$, Diego Jiménez-López ${ }^{2}$, \\ Ángel García-Crespo ${ }^{1}$, and Borja Blanco-Iglesias ${ }^{3}$ \\ ${ }^{1}$ Universidad Carlos III de Madrid, Computer Science Department \\ Av. Universidad 30, Leganés, 28911, Madrid, Spain \\ \{ricardo.colomo, angel.garcia\} @uc $3 \mathrm{~m}$.es \\ ${ }^{2}$ EgeoIT \\ Av. Brasil 17, 28020, Madrid, Spain \\ diego.jimenez@egeoit.com \\ ${ }^{3}$ Deloitte DxD, \\ Plaza Carlos Trías Beltrán 7, 28020, Madrid, Spain \\ borja@babieca.org
}

\begin{abstract}
Learning educative processes are a challenge for educative institutions and education professionals. In an environment in which learning resources are being produced, catalogued and stored using innovative ways, SOLE provides a platform in which exam questions can be produced supported by Web 2.0 tools, catalogued and labeled via semantic web and stored and distributed using eLearning standards. This paper presents, SOLE, a social network of exam questions sharing particularized for Software Engineering domain, based on semantics and built using semantic web and eLearning standards, such as IMS Question and Test Interoperability specification 2.1.
\end{abstract}

Keywords: Semantic Web; Web 2.0; E-Learning; Learning Community; Software Engineering.

\section{Introduction}

Distance Education, also known as open, flexible or distributed learning, is a mode of education whereby learners are physically separated from the institution and where the learning process takes place outside the education establishment [1]. Due to the undeniable importance of the Internet, online learning and online learning tools are hot topics for educational community. However, this new kind of learning scenario has proponents, adversaries and spectators [2]. One of the advantages of such environments is that now these environments self-sustainable and do not have a teacher present to supervise and mentor the learning and communication processes [3]. But to take full advantage of this, e-learning resources must be well designed and open for everybody. 
When we talk about the development of the web and where we stand today, we stumble across two main buzzwords: Web 2.0 and semantic web [4]. The new surroundings in which we find ourselves imply a technology enhanced learning, which Downes [5] calls e-learning 2.0. According to [6], learning systems evolve now towards Web 2.0, semantic web and also improving the learning process.

On the one hand Web 2.0 is about participation and reuse [4]. In the last few years, there has been an increasing focus on social software applications and services as a result of the rapid development of Web 2.0 concepts [7]. Web 2.0 technologies as outlined in [8] are exemplified by blogs, namely easy to update websites about a particular subject where entries are written in chronological order, picture-sharing environments such as Flickr or Photobucket, social bookmarking sites such as Del.icio.us, video-sharing such as YouTube or music preferences such as Last FM. Web 2.0, social software, social computing, online communities, peer networking, immersive web. This architecture promotes users' participation through blogs, wikis and folksonomies, turning learners into knowledge prosumers [9].

On the second hand, Semantic web represents a revolution in many senses. The term "Semantic Web" was coined by Berners-Lee, Hendler \& Lassila [10], to describe the evolution from a document-based web towards a new paradigm that includes data and information for computers to manipulate. The Semantic Web provides a complementary vision as a knowledge management environment [11] that, in many cases has expanded and replaced previous knowledge and information management archetypes [12]. In this new scenario, the challenge for the next generation of the Social and Semantic Webs is to find the right match between what is put online and methods for doing useful reasoning with the data [13]. Given that challenge, semantic web and ontologies is seen as the key for forthcoming eLearning solutions [14].

Taking into account that the application of Information and Communication Technologies, towards more effective learning, is one of the most challenging contexts given the specific characteristics of the learning domain [15], in this paper we present SOLE. SOLE can be described as a social network of exam questions particularized for Software Engineering domain, based on semantics and built using semantic web and eLearning standards.

The remainder of the paper is organized as follows. Section 2 outlines relevant literature in the area about the field of study. In Section 3, the architecture for the SOLE approach is presented along with the description of the implementation of the proof of the concept architecture. Conclusions and future work are discussed in Section 4.

\section{State of the Art}

The great diffusion of Web 2.0 is having a tremendous effect in education and learning. Thus, the number of Web 2.0 empowered e-learning environments are booming [16]. Much of what goes by the name of Web 2.0 can, in fact, be regarded as new kinds of learning technologies, and can be utilized as such [17]. e-learning systems evolve to adapt their contents to this new tools provided by means of the Social Web including under their umbrella social networks blogs, wikis, microblogs [18]... Examples of the use of web 2.0 technologies in eLearning can be found in the works of [19], [20], [21] to cite just a few. 
On the other hand, semantic technologies are gaining momentum in eLearning environments. In the e-Learning field, Brase and Nejdl [22] have showed the increasing importance of knowledge modeling through metadata definition standards. Semantic Web has been pointed out to be beneficial for learning environments, in so far as ontologies can effectively model and interrelate information describing learning content, learning activities and learners; and thus improving content personalization and feedback provisioning [23].

In spite of the incompatibility problem between metadata descriptions, an increasing number of systems have been developed to handle learning resources by means of Semantic Web technologies [24], [25], [26], [27], [28], [29], [30]. Following this research trend, in this paper, we present SOLE, a social network based tool for exam questions exchange and sharing based on social and semantic web.

\section{The SOLE Approach}

As stated before, SOLE can be seen as a platform in which exam questions can be produced supported by Web 2.0 tools, catalogued and labeled via semantic web and stored and distributed using eLearning standards. To do so, SOLE is based on state of the art technologies and defined standards.

\subsection{Overview Architecture}

SOLE is based on component-based client server architecture. Each component is independent from the others but can be invoked using Enterprise JavaBeans (EJBs) 3.0. Figure 1 shows main components as well as their connections.

- Service Handler: Focal point to web service invocation.

- Question Manager: implements basic task related to question persistence (insert, delete, update...).

- QTI Translator: enables the transformations from questions stored in the database to QTI XML complaint format or vice versa. QTI is Question and Test Interoperability specification, a standard format for the representation of assessment content and results. Using QTI applications can exchange education materials allowing more open and rich eLearning platforms.

- User Manager: basic tasks related to user management.

- Session Manager: enables login and logout features as well as session log.

- User Communicator: event driven agent in charge of communicate users certain events.

- Social Network Manager: handler related to social web users networks.

- Search: Consist in two main subcomponents. Firstly, Indexer will manage question index. Secondly, Seeker, that uses this index to give desired results.

- Semantic Engine. Clasifies questions (invoked by Indexer) and classifies search queries (invoked by Seeker). This implementation of SOLE acts as 
a Software Engineering eLearning enabler, and due to this, Software Engineering Ontology (SEOntology) was used as a testbed.

- Knowledge manager. It's responsible of the management of the tasks in order to train Semantic Engine using user suggested terms.

- Syndication. Manages RSS feeds generated due to the use of SOLE. This feeds can be viewed using external RSS readers.

- Manager. Capable of encapsulating configuration and maintenance tasks related to server.

- Daemon. Agent that acts as a daemon to trigger administration and maintenance tasks.

- Web. Web interface for SOLE.

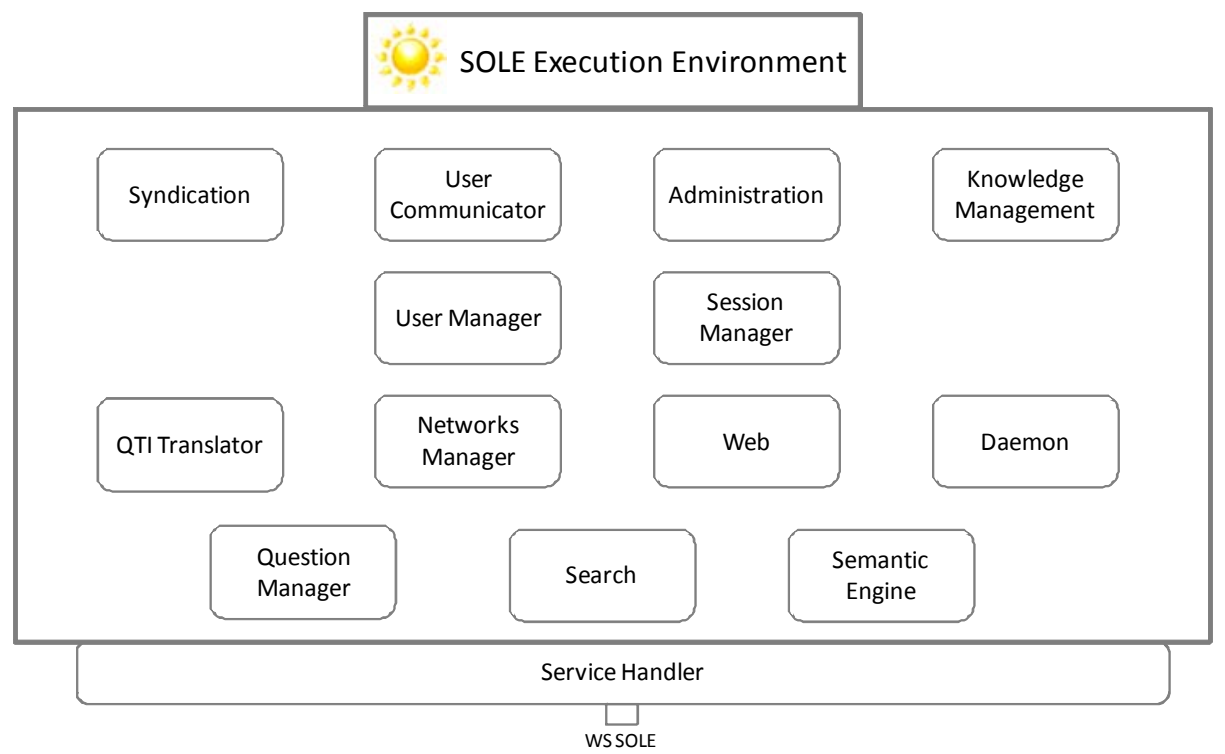

Fig. 1. SOLE global module architecture

\subsection{Implementation Issues}

SOLE can be seen as a Web based application build under Java EE (by using Java Enterprise Edition 5 SDK). Business logic design was done using MagicDraw. This tool enables Model Driven Architecture (MDA) architecture and automatic code generation by using AndroMDA.

External interfaces are enabled using Service-oriented architecture (SOA). Backend is designed using Hibernate and MySQL as database management system. Frontend is designed using ZK framework for AJAX integrated in Eclipse Ganymede through ZK Studio plug-in. Lastly, JAXB is used for XML handle (in order to communicate with others) and JENA 2 for ontology information issues. Finally, in order to enable RSS feeds and atom, ROME for Apache 2.0 is used. 


\subsection{Initial Testing}

With the aim of getting feedback concerning the work performed, SOLE was implanted as a tool to support learning processes in their last year of the Computer Science degree program, "Software Engineering III" in Universidad Carlos III de Madrid, Spain. In such scenario, the students were asked to use SOLE tool as support for their course. The class was divided into groups. Every group must provide and label a set of questions (twenty five) to the system based on the course syllabus. These combined actions trained in a proper way the system. Once all questions were typed and stored, students were provided with a tool, namely SeSo-GEO in which they could build an exam for the rest of the groups. SeSo-GEO benefits from SOLE features of semantic search via web service. Exams provided by students consisted in ten questions from the questions base and are aimed to train groups in course syllabus.

Qualitative results of this test were successful. Students agreed that semantic search provides a plus to the system ('reaching results that are hidden in the text') and, moreover, that "having a way to rank questions is a powerful tool to choose better questions".

\section{Conclusions and Future Work}

Combining Semantic Web and social networks is considered the future in eLearning platforms and solutions. In such a context, sharing and taking advantage of a number of users, tracing knowledge and contents in different contexts can bridge the gap of knowledge integration and knowledge reuse. In this paper, we have presented a novel approach to achieve test question share and reuse across learning environments through a social network and the use of semantics and eLearning standards, providing also an architecture and a proof-of-concept implementation.

The current work proposes three types of initiatives which should be explored in future research. In the first place, the integration of the functionalities provided by Web 2.0 in the mark of questions from the point of view of the student, giving, thus a double feedback from the field: students and teachers. In the second place, it is aimed to test the platform developed empirically by evaluating the capabilities of SOLE from a qualitative viewpoint. Finally, authors suggest extending the functional environment of SOLE to adapt other learning scenarios.

\section{References}

1. Porto, F., de Carvalho Moura, A.M., Coutinho da Silva, F.J., Pereira Fernandez, A.: The ROSA project: leveraging e-learning to a semantic layer. Int. J. Knowledge and Learning 3(1), 46-75 (2007)

2. Ruth, A.: Learning in a mediated online environment. Int. J. Technology Enhanced Learning 1(1/2), 132-143 (2008)

3. Laghos, A., Zaphiris, P.: Social network analysis of self-taught e-learning Communities. Int. J. Knowledge and Learning 3(4/5), 465-482 (2007)

4. Lux, M., Dösinger, G.: From folksonomies to ontologies: employing wisdom of the crowds to serve learning purposes. Int. J. Knowledge and Learning 3(4/5), 515-528 (2007) 
5. Downes, S.: E-learning 2.0, eLearn Magazine (2005),

http: //www.elearnmag.org/subpage.cfm?section=articles\&articl

e=29-1 (retrieved December 18, 2008)

6. Yang, H.C.: A method for automatic construction of learning contents in semantic web by a text mining approach. Int. J. Knowledge and Learning 2(1/2), 89-105 (2006)

7. Chatti, M.A., Jarke, M., Frosch-Wilke, D.: The future of e-learning: a shift to knowledge networking and social software. Int. J. Knowledge and Learning 3(4/5), 404-420 (2007)

8. Laudon, K.C., Laudon, J.P.: Management Information Systems: Managing the Digital Firm, 10th edn. Prentice Hall, Upper Saddle River (2006)

9. Carchiolo, V., Correnti, D., Longheu, A., Malgeri, M., Mangioni, G.: Exploiting trust into e-learning: adding reliability to learning paths. Int. J. Technology Enhanced Learning 1(4), 253-265 (2009)

10. Berners-Lee, T., Hendler, J., Lassila, O.: The semantic web. Scientific American 284(5), 34-43 (2001)

11. Warren, P.: Knowledge management and the semantic web: From scenario to technology. IEEE Intelligent Systems 21(1), 53-59 (2006)

12. Davies, J., Lytras, M.D., Sheth, A.P.: Semantic-web-based knowledge management. IEEE Internet Computing 11(5), 14-16 (2007)

13. Gruber, T.R.: Collective knowledge systems: Where the social web meets the semantic web. Web Semantics: Science, Services and Agents on the World Wide Web 6(1), 4-13 (2008)

14. Vargas-Vera, M., Lytras, M.D.: Exploiting semantic web and ontologies for personalised learning services: towards semantic web-enabled learning portals for real learning experiences. Int. J. Knowledge and Learning 4(1), 1-17 (2008)

15. Lytras, M., Ordóñez, P., Mantziou, M.: Information and communication technologies and management of education. Int. J. Management in Education 1(3), 193-198 (2007)

16. Sigala, M.: Integrating Web 2.0 in e-learning environments: a socio-technical approach. Int. J. Knowledge and Learning 3(6), 628-648 (2007)

17. Rollett, H., Lux, M., Strohmaier, M., Dosinger, G., Tochtermann, K.: The Web 2.0 way of learning with technologies. International Journal of Learning Technology 3(1), 87-107 (2007)

18. Alexander, B.: Web 2.0: A new wave of innovation for teaching and learning? EDUCAUSE Review 41(2), 32-44 (2006)

19. Marenzi, I., Demidova, E., Nejdl, W., Zerr, S.: Social software for lifelong competence development: Challenges and infrastructure. International Journal of Emerging Technologies in Learning 3(2), 18-23 (2008)

20. Ras, E., Avram, G., Waterson, P.E., Weibelzahl, S.: Using weblogs for knowledge sharing and learning in information spaces. Journal of Universal Computer Science 11(3), 394-409 (2005)

21. Gaeta, M., Miranda, S., Ritrovato, P.: ELeGI as enabling architecture for e-learning 2.0. Int. J. Knowledge and Learning 4(2/3), 259-271 (2008)

22. Brase, J., Nejdl, W.: Ontologies and Metadata for eLearning. In: Handbook on Ontologies, pp. 555-574 (2004)

23. Jovanović, J., Gašević, D., Brooks, C., Devedžić, V., Hatala, M., Eap, T., Richards, G.: Using Semantic Web Technologies for the Analysis of Learning Content. IEEE Internet Computing 11(5), 45-53 (2007)

24. Nejdl, W., Wolf, B., Qu, C., Decker, S., Sintek, M., Naeve, A., Nilsson, M., Palmer, M., Risch, T.: EDUTELLA: A P2P Networking Infrastructure Based on RDF. In: Proceedings of the 11th international conference on World Wide Web, Honolulu, Hawaii, USA, pp. 604-615 (2001) 
25. Tane, J., Schmitz, C., Stumme, G., Staab, S., Studer, R.: The Courseware Watchdog: an Ontology-based tool for finding and organizing learning material. In: Fachtagung Mobiles Lernen und Forschen, Kassel (2003)

26. Stutt, A., Motta, E.: Semantic Learning Webs. Journal of Interactive Media in Education 2004(10) (2004)

27. Devedzic, V.: Education and the Semantic Web. International Journal of Artificial Intelligence in Education 14, 39-65 (2004)

28. Millard, D.E., Doody, K., Davis, H.C., Gilbert, L., Howard, Y., Tao, F., Wills, G.: (Semantic web) services for e-learning. Int. J. Knowledge and Learning 4(2/3), 298-315 (2008)

29. Gaeta, M., Orciuoli, F., Ritrovato, P.: Advanced ontology management system for personalised e-Learning. Knowledge-Based Systems 22(4), 292-301 (2009) 